
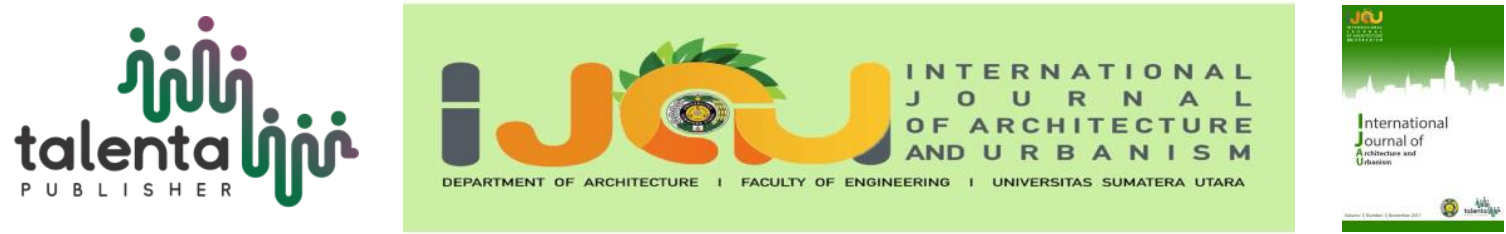

\title{
Study of User Perception of A Room (Case Study: Architecture Building)
}

\author{
Ulfa Auliyah $^{1 *}$, M. Nawawiy Loebis ${ }^{1}$ \\ ${ }^{1}$ Architecture Department, Faculty of Engineering, Universitas Sumatera Utara, Medan, Indonesia
}

\begin{abstract}
Space cannot be separated from human life, both psychologically emotional (perception) and dimensional. Humans are moving and living, thinking, and also creating space to express the shape of their world and formed when people react to the environment in giving meaning to their environment. It can be said that environmental evaluation, furthermore, is a response to the overall influence of a detailed analysis of specific aspects, and more of a compared to the manifest function and is strongly influenced by images. This paper explains the results of the study, which intends to find out student perceptions of the meaning of space in the Architectural building of the Faculty of Engineering, University of North Sumatra. The study uses data analysis methods. The results of the study show that students' perceptions of space use are not by the allocation of the Department of Architecture, Faculty of Engineering, University of North Sumatra, because it is influenced by culture, space settings, and accessibility. The benefits of this study as a reference to the Department of Architecture of the University of North Sumatra to be able to improve the quality of teaching and to learn in supporting the comfort of student learning.
\end{abstract}

Keyword: meaning of space, perception, space.

\section{Introduction}

Space also has no meaning if there are no humans. Human behavior itself is understood as a set that is possessed by humans and is influenced by the customs, attitudes, emotions, and perceptions of each. This perception is a process taken by each to organize and interpret impressions from their senses to the surrounding environment.

As a field of science related to art, architecture is not only seen in terms of aesthetics but also has a deeper meaning than a function of building the value of an architectural work that is the form of mass and space organization. However, the purpose of architectural design is problemsolving in response to the conditions of the function and scope architecturally.

Based on this, the study intends to find out students' perceptions of the meaning of space in the building of the engineering faculty of the University of North Sumatra where the Department of

*Corresponding author at: Departement of Architecture, faculty of Engineering, Universitas Sumatera Utara,

Jalan Perpustakaan, Building J07, Medan 20155, Indonesia

E-mail address: ulfaauliyah81@yahoo.com 
Architecture is a department that deals with art and requires creativity, so that to support this creative power must be supported with spaces in the building Architecture.

\section{Literature Review}

Perception is part of the life process that is owned by each person, from a person at a certain point, then that person creates things he sees for his world, then the person tries to take advantage of his satisfaction[1]. Architecture means creating space in a way that is planned and thought out. Continuous architectural renewal is rooted in changing the concepts of space[2]. Then Activities occur in settings then proceed that the activity system in the setting system as well as situations, rules, and behaviors communicated through signals occurring in settings. This explains that activity is linked through meaning, in other words, that the principle of the mechanism that connects is the meaning[3].

\section{Methodology}

This study uses data analysis methods by conducting direct observations, interviews, and distributing questionnaires whose respondents are students of the USU FT Architecture Department. Data analysis focused on the influence of activities in forming relationships between spaces and student perceptions of space used in the USU FT Architecture Department building.

\section{Result and Discussion}

The Department of Architecture is located street Library Building J-07, Padang Bulan, Medan Baru, Medan City, North Sumatra. The Building Department of Architecture, University of North Sumatra, has two buildings, namely the old building and the new building (Figure 1).

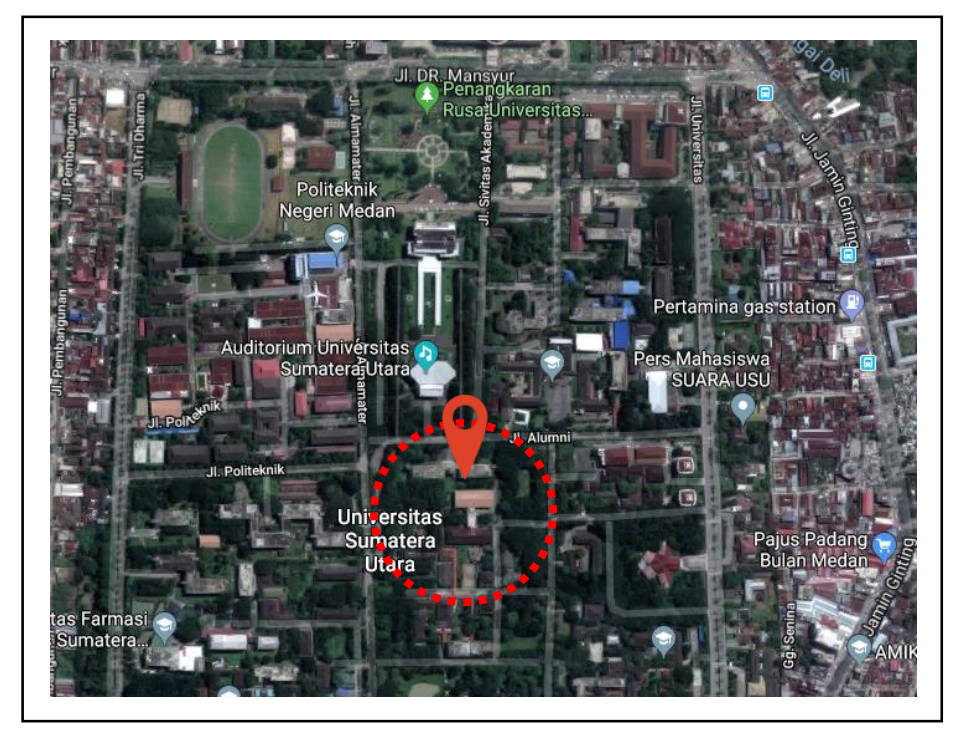

Figure 1. Location Map 
The architecture of the University of North Sumatra has two floors with space requirements such as administration room, USU Architecture department chair room, hall, studio, library, toilet, laboratory, etc. (Figure 2)

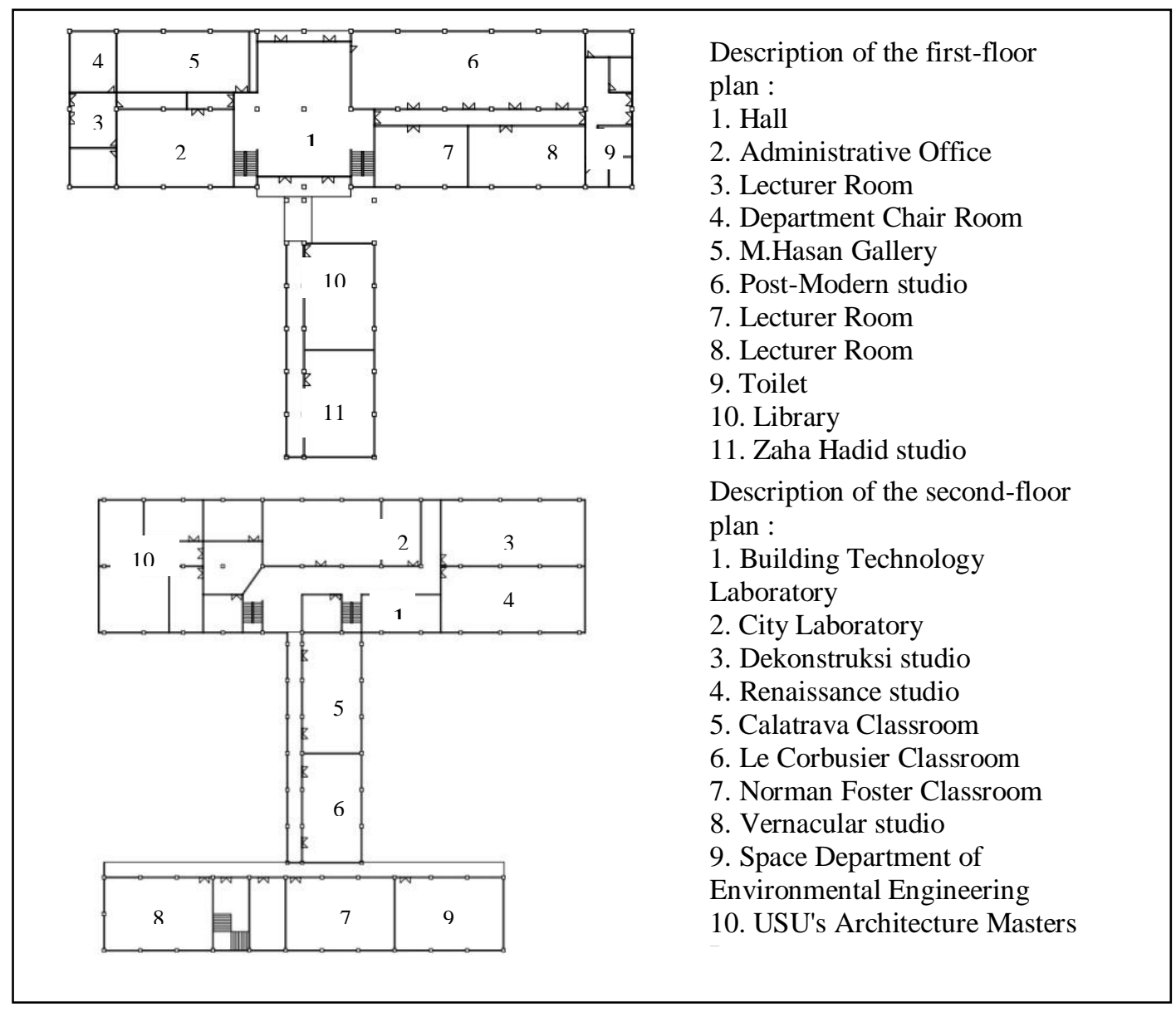

Figure 2. Building Plan

Activities and spaces are closely related because space has no meaning if there is no activity in it. When activity occupies space, there will be a tendency where the occurs in space. In a lecture building, activities that occupy space can occur, for example, in the form of a square, even though the shape is an irregular square. Also, activities can also occur in spaces with linear patterns such as access roads or corridors. From the identification of the functions of the spaces in the USU Architecture building and the identification of activities in the spaces in the USU Architecture building produced several areas of space that did not fit the function.

Parking area

The ideal parking system is a system that takes into account the function of the area, the function of the road service, the volume of traffic and the direction of movement. The allocation of the Department of Architecture in the use of parking lots is for parking 2-wheeled and 4wheeled vehicles. But the perception of students is more convenient to use for parking 4- 
wheeled vehicles near the college building. Student policies are found that utilize the accessibility of buildings that are used as parking (Figures 3 and 4).

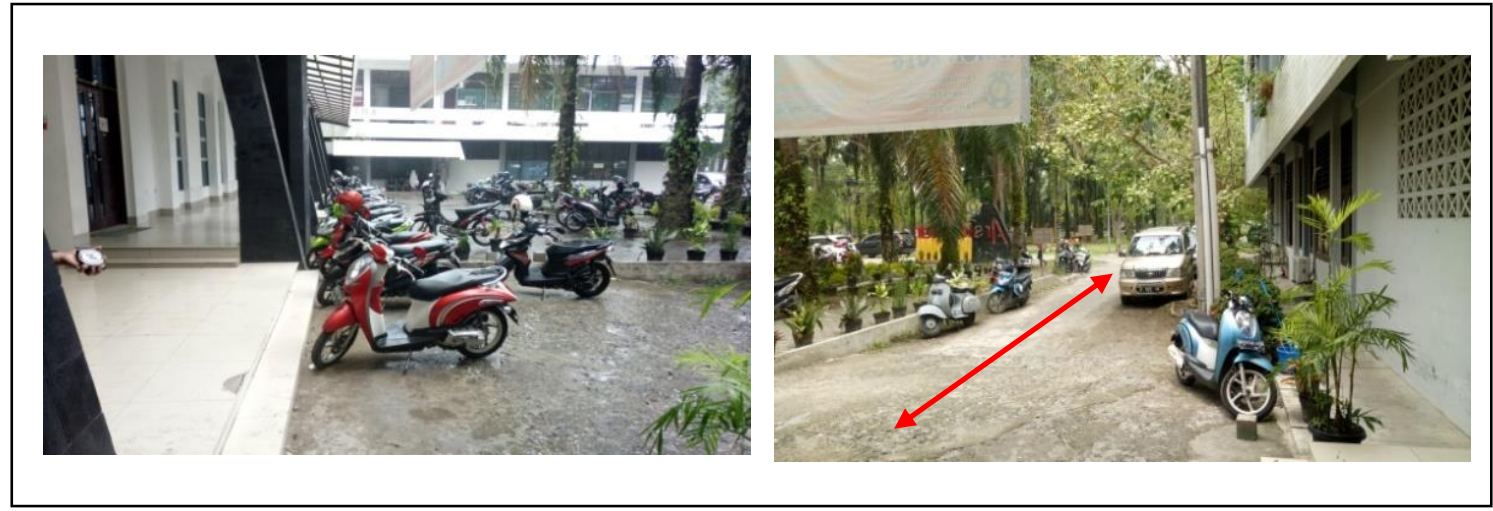

Figure 3. Access to the Building

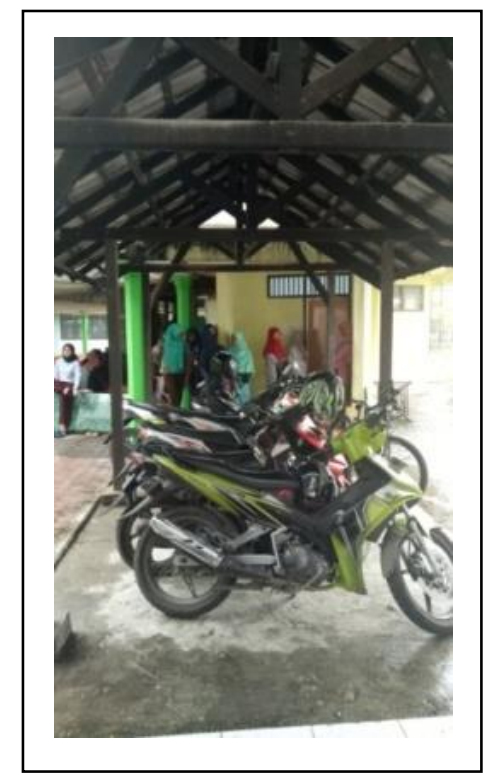

Figure 4. Access to Musholla

\section{Circulation}

The circulation is functioned as a liaison between spaces but, students still make a lot of the hall as a point to gather. Access to meet on the ground is more frequent and comfortable than having to sit in a chair that has been provided hall (Figure 5). Associated with spatial settings that are very close to classrooms and user behavior towards spatial planning by the hope of students (Figure 6). 


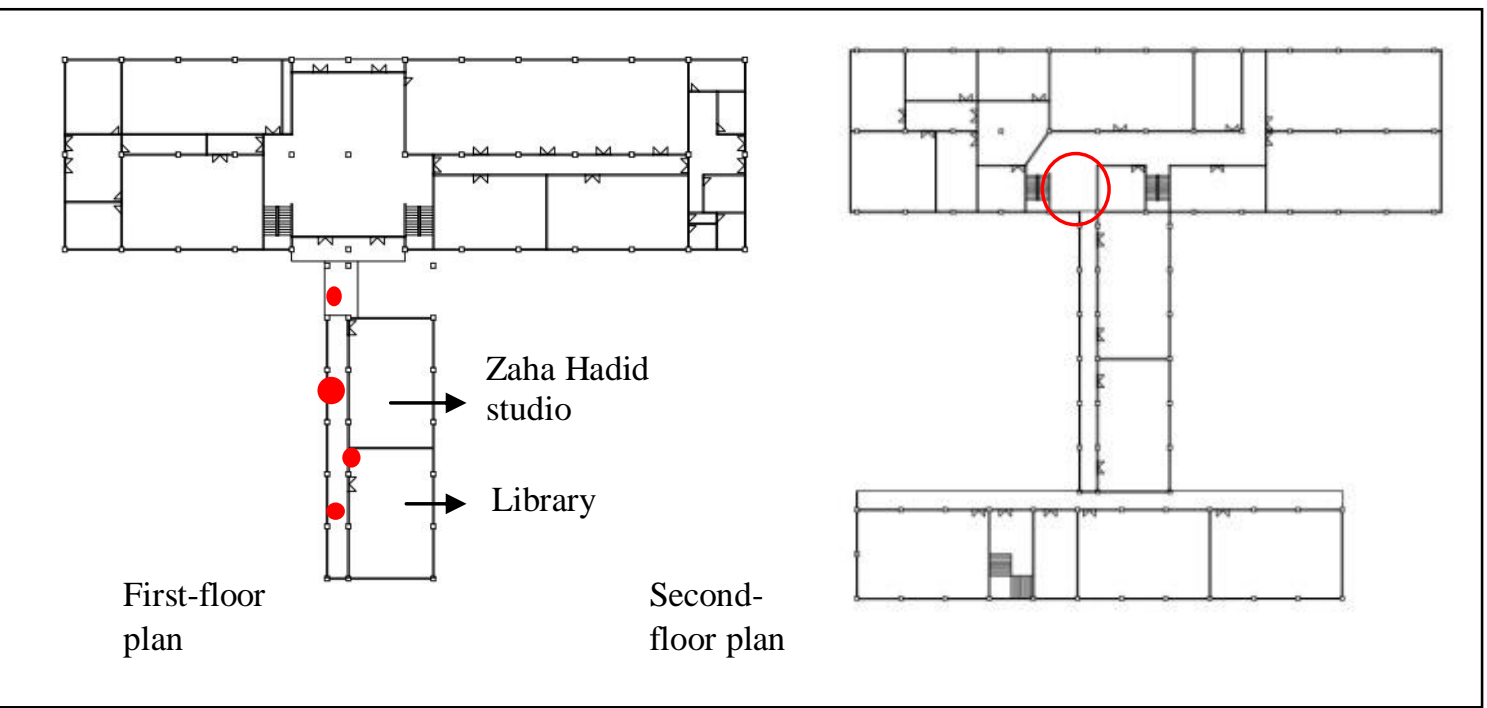

Figure 5. Student Gathering Point

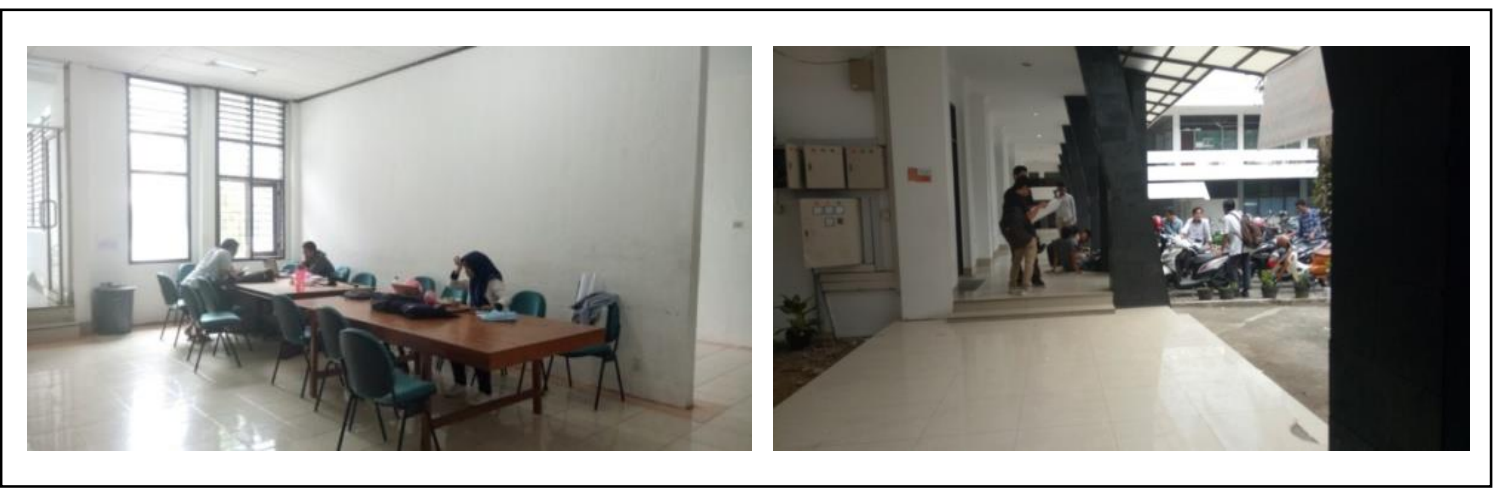

Figure 6. The atmosphere in the Building Circulation

\section{Library}

The function of the library is not only a collection of books and reading places. College libraries are used by students to do assignments. Students prefer to do college work in the library because the source is complete and also equipped with wifi. The library has functioned as a place to read and discuss students, but students prefer the library as a place to do the assignments. This is related to the room setting that is made cool by adding air conditioning in the library, considering the space that is the privacy of each (Figure 7). 


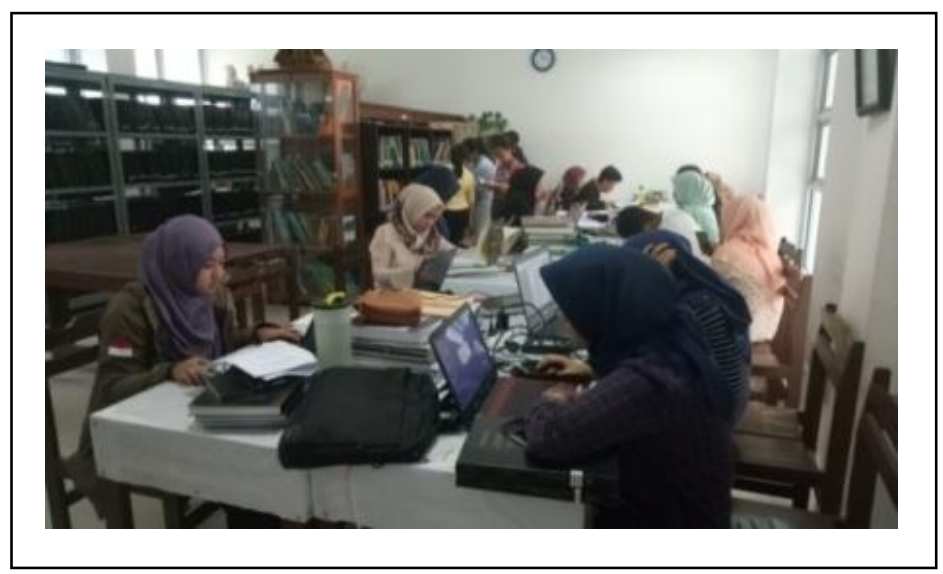

Figure 7. The atmosphere in the Library

\section{Administration Room}

The administration room is functioned as a place to take care of campus administration and space for discussion between lecturers. The large table in the Administration room was considered by the students as a room of assistance, the lecturer was at the desk, and the students immediately met the lecturer so that the process of assistance was spontaneous. This is related to accessibility that is close enough to be easily accessible. The meaning of the intermediate level is related to the room setting that functions into two, namely as an administrative space and socialization space and a high level of meaning related to culture, preferring to directly meet with lecturers rather than having to make an appointment first (Figure 8).

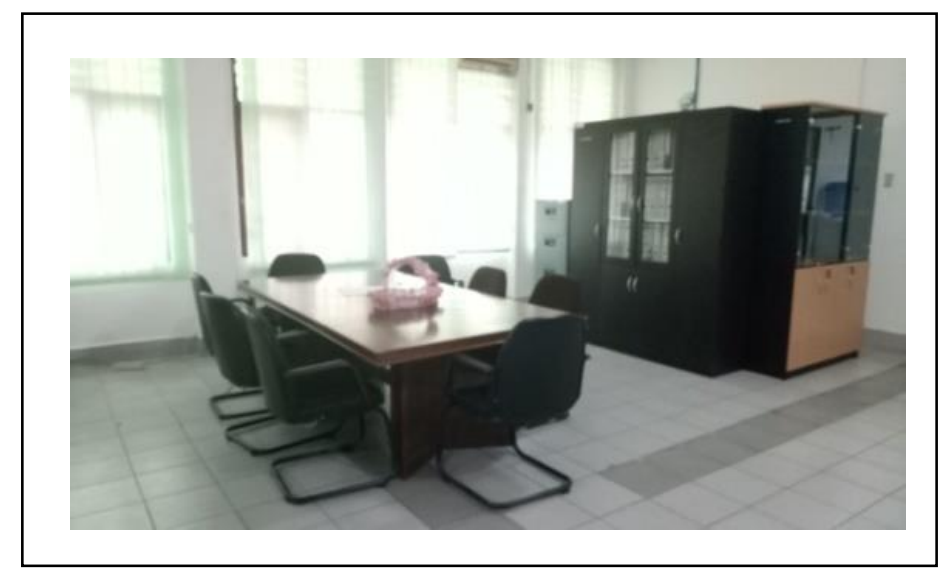

Figure 8. Administration Room

\section{City Planning Laboratory Room}

City laboratories functioned as a place of assistance to lecturers in urban planning or related to urban planning. There are a large table and chairs used for assistance, but students put their assignments like models on the table due to lack of space. The lack of space for the exhibition caused students to accumulate models in several rooms. This is related to the lack of room settings for assigning student tasks (Figure 9). 


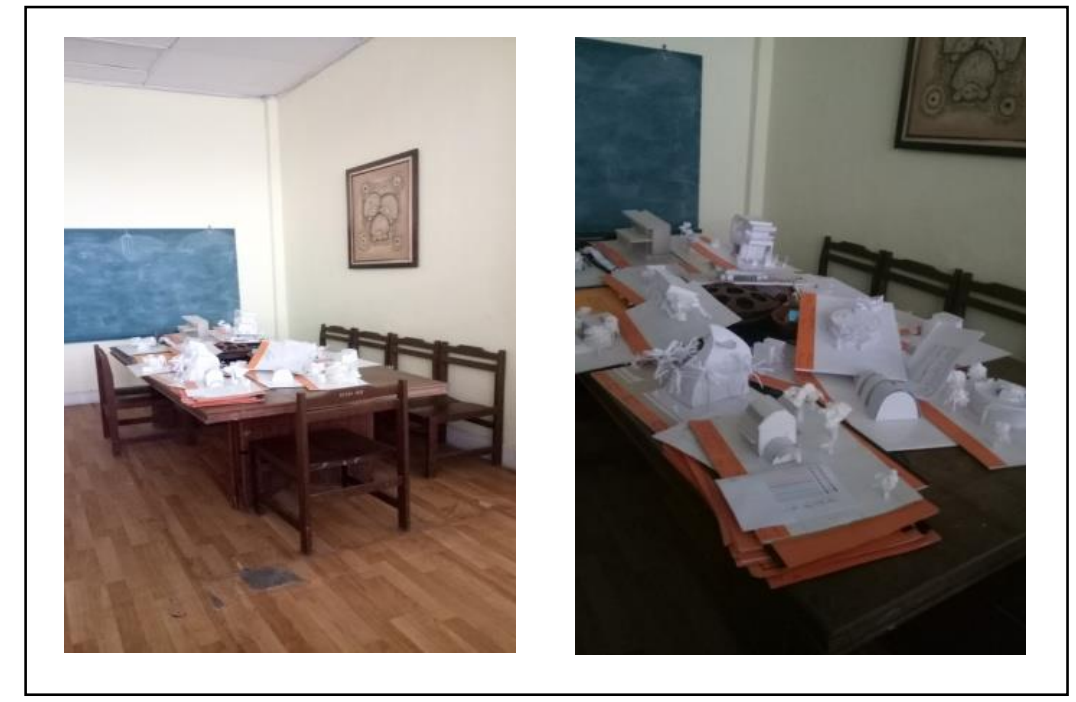

Figure 9. Administration Room

Rooftop

Rooftop functioned as a workshop and student activities. Lack of care and not managed properly, the rooftop is used as a place of unused goods and student activity equipment. Related to culture, students who consider space that is no longer used are used as a place for items that are no longer used (Figure 10).

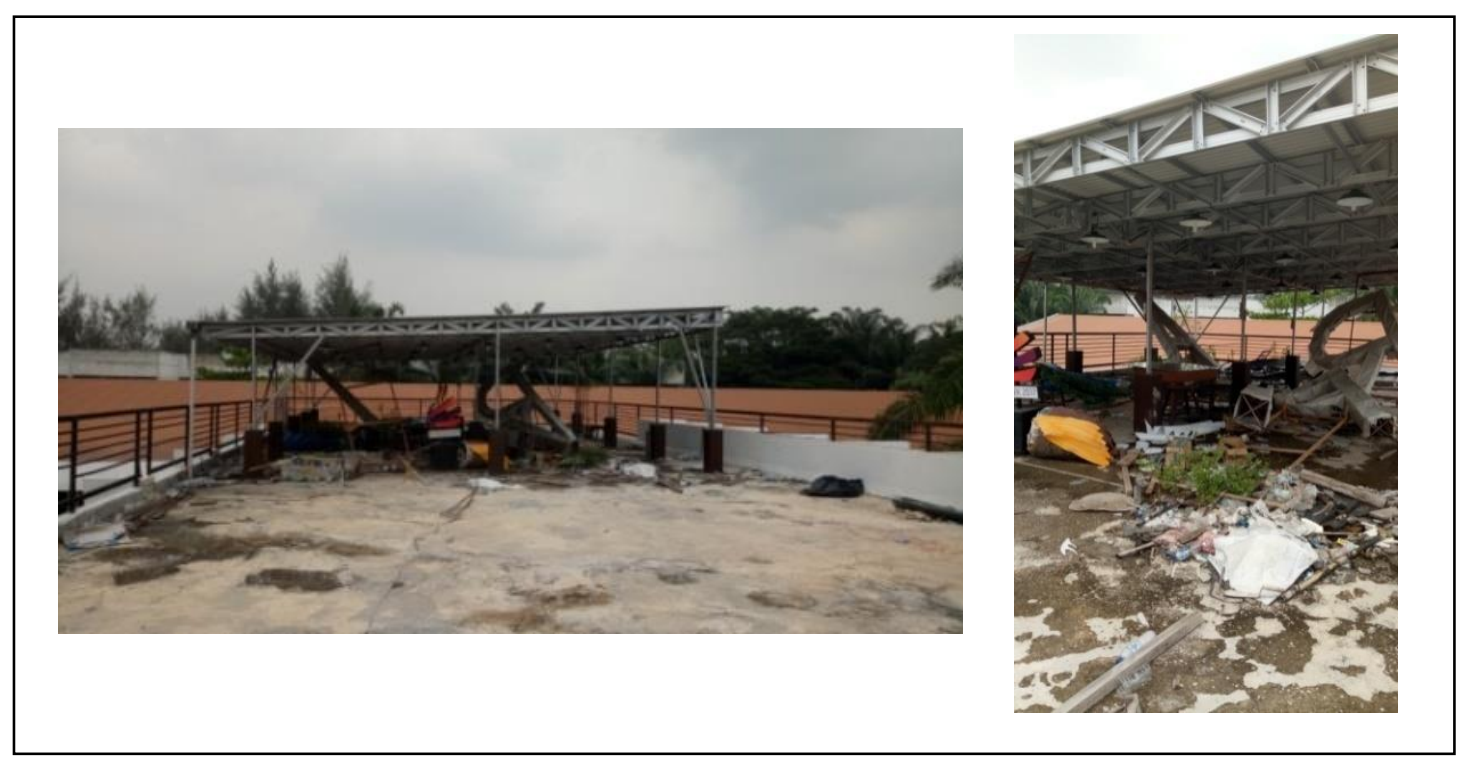

Figure 10. Rooftop Area

\section{Conclusion}

A person's response to his environment depends on how the individual concerned perceives his environment. One of the things that humans perceive about their environment is the space around them, both natural space and artificial space. The social aspect is how humans share, and share space with each other and humans have individual personalities, but humans are also social beings, living in the society in a collectivity. In fulfilling this social need, human beings 
behave socially in their environment which can be observed from behavioral-environmental phenomena, user groups and the place where activities occur.

\section{Acknowledgment}

This article was prepared by researchers as a part of funding by Universitas Sumatera Utara to the City Government to dedicate expertise in the field of architecture based on local wisdom in planning and design.

\section{REFERENCES}

[1] J. Lang, "Creating Architectural Theory, The Role of The Behavioral Sciences in Environmental Design, Van Nostrand Reinhold Company Inc, New York," 1987.

[2] J. L. Kartono, "Ruang Manusia dan Rumah Tinggal Sautu Tinjauan Persfektif Kebudayaan," DIMENSI (Journal of Architecture and Built Environment), p. 27, 2004.

[3] J. O. Waani, "Teori Makna Lingkungan dan Arsitektur," Media Matrasain, pp. 36-47, 2012. 